\title{
$C E_{S} A$
}

Centro de Estudos sobre África e do Desenvolvimento

Instituto Superior de Economia e Gestão da Universidade Técnica de Lisboa

Colecção

Documentos de Trabalho

$$
n^{o} 101
$$

Bruno Damásio e Luís Mah

\section{Das limitações do PIB enquanto indicador às necessidades de medição dos níveis de Desenvolvimento}


O CEsA não confirma nem infirma quaisquer opiniões expressas pelos autores nos documentos que edita. 
Das limitações do PIB enquanto indicador às necessidades de medição dos níveis de Desenvolvimento

Bruno Damásio e Luís Mah

\author{
CEsA \\ Centre of African and Development Studies \\ Faculty of Economics and Management \\ Technical University of Lisbon
}




\section{Resumo}

Este trabalho procura problematizar algumas limitações e insuficiências dos utensílios tradicionais de medição da performance económica e de desenvolvimento dos Estados, como o Produto Interno Bruto (PIB) Comenta-se sinteticamente alguns índices que, com vários âmbitos, tentam complementar esta grandeza. Salienta-se a necessidade da consolidação e do estímulo do aperfeiçoamento de indicadores e medidas alternativas, de forma a diminuir as deficiências existentes nas actuais medições do desenvolvimento que servem de referência.

Palavras-Chave: competitividade entre estados, desenvolvimento, desenvolvimento humano, índice, produto interno bruto, sistema de contas nacionais.

Journal of Economic Literature (JEL): C81, C82, 010, O19, Y10, Y29. 


\section{Introdução}

Utilizando enquanto válida a definição de economia de alocação de recursos escassos a necessidades ilimitadas, chegamos a uma concepção de política económica enquanto a actuação dos poderes públicos em domínios económicos destinada à obtenção de resultados previamente escolhidos (Amaral, 1996). Interessa, então, reflectir sobre o facto de que, sem a construção de instrumentos e indicadores estatísticos que permitam avaliar as consequências e interpretar os resultados decorrentes da aç̧ão política, dificilmente será possível uma orientação consistente da tomada de decisão de política económica. É neste âmbito que encetamos o nosso ensaio com uma meditação a propósito da eventual debilidade do indicador de actividade económica mais utilizado pelos economistas e políticos mainstream.

Assim, foi com o processo de consolidação dos sistemas de contas nacionais, iniciado, sensivelmente, na década de 40 do passado século, com alguns ajustes pelo meio, que se afirmou o Produto Interno Bruto (PIB), soma das produções das empresas e demais sectores institucionais que actuam num dado país menos os seus consumos intermédios, enquanto o indicador de excelência da performance económica dos Estados.

No entanto, existe toda uma realidade multidimensional em torno dessa perfomance económica que a medida de mensuração em causa não consegue abarcar. Donde, o PIB traduz-se num indicador insuficiente e insatisfatório, sendo, aliás, alvo de discussão e de problematização ao longo dos tempos, pois, na prática, o PIB não mede nem o bem-estar nem a felicidade das pessoas.

Por conseguinte, não se reflectem no PIB nem os danos ambientais, nem a delapidação dos recursos naturais colectivos do planeta. Assim, por exemplo, as crescentes emissões de $\mathrm{CO}_{2}$ decorrentes da actividade produtiva não são contabilizadas como um custo social. Por outro lado, as actividades, por hipótese, de extracção de petróleo que, concorrem para a actividade económica e, por conseguinte, para o aumento do PIB, contribuem, igualmente, para o esgotamento dos recursos globais naturais, embora não exista aqui nenhuma contabilização dos danos causados.

Outra das limitações do PIB é a de não contabilizar trabalho doméstico e o trabalho voluntariado não remunerado, subestimando, deste modo, o valor das produções nacionais. Ainda no que concerne ao voluntariado chamamos a atenção para um fenómeno algo contraditório. Desta feita, se uma associação, numa determinada região, se dedicar a campanhas de saúde preventiva, daí decorrem reduções da mortalidade infantil, bem como do número de hospitalizações, por conseguinte, da taxa de doentes e, obviamente, do consumo de medicamentos, logo, um aumento de bem-estar dos indivíduos. Por outro lado, do ponto de vista económico, tal redução do consumo de medicamentos implica uma quebra no PIB, o que, naturalmente, evidencia a ideia, referida há pouco, da escassa capacidade do PIB em espelhar o bem-estar dos indivíduos.

Finalmente, como sugere Dowbor, a restrição do acesso a bens públicos pode, também, originar um aumento do PIB. Apontando o exemplo duma medida, como a da restrição do acesso gratuito a determinadas praias, o autor conclui que tal decisão, embora, em primeira instancia, reduzisse o bem-estar colectivo, na medida em que diminuiria o usufruto das praias, contribuiria, antagoniconicamente, para um aumento do PIB. Donde, a busca de se restringir a mobilidade, o espaço livre de passeio, o lazer gratuito, gera o que hoje chamamos de economia do 
pedágio, de empresas que aumentam o PIB ao restringir o acesso aos bens. Temos uma vida mais pobre, e um PIB maior. Dowbor (2006, p.3)

Deste modo, em concomitância com a discussão em torno das deficiências do PIB enquanto grandeza de medição, foram vindo a ser propostas medidas alternativas capazes de captar e reproduzir a realidade ambiental, sócio institucional e o bem-estar societal.

Neste sentido, já no século XXI, um conjunto de especialistas, entre os quais os economistas Joseph Stiglitz, Amartya Sen e Jean-Paul Fitoussi, no âmbito da Comissão para a Medição do Progresso Económico e Social, elaborou um relatório ${ }^{1}$ que, reconhecendo as limitações do PIB, procurou avaliar a viabilidade de outras medidas, centradas na comensuração do bem-estar das populações em detrimento da mensuração da produção económica.

Assim, constatando que o PIB, em particular o PIBpc é uma medida que exprime a média do rendimento de um determinado país, enfatiza a necessidade de se comensurar as desigualdades na distribuição do rendimento. Por outro lado, propõe uma série de recomendações quanto à medição da dimensão, multifocal, do bem-estar dos indivíduos, relacionadas não só com questões materiais, mas também com questões de saúde, educação, trabalho, governação, coesão social, ambiente e segurança.

Importa ainda referir que as discussões em torno desta problemática não são um fenómeno recente. Desta feita, lembramos aqui o contributo de Jigme Singya Wangchuck que, no Butão, na década de setenta do século XX, encetou a concepção do indicador da Felicidade Interna Bruta (FIB $)^{2}$ e, apoiado pelo PNUD, a formação do Centro de Estudos do Butão (CBS). O FIB, através do cruzamento de métodos quantitativos com métodos qualitativos, intenta em mensurar o bem estar dos indivíduos, isto é, o seu nível de satisfação quanto a questões de educação, saúde, protecção ambiental, governação, economia e de demais liberdades, direitos e garantias. Assim, uma vez mais, é apresentada a tese de que a dimensão do nível de actividade económica patente no PIB não é tão avisada quanto a das perspectivas enunciadas atrás.

Num outro plano, no final da década de 60 do século XX, o economista paquistanês Mahbub ul Haq alertou para o facto de, em certa medida, uma elevada taxa de crescimento económico de um estado não ser, por si só, garante de progresso social, institucional, de bem estar e de desenvolvimento. Apontou o exemplo do contexto paquistanês da sua época, onde se atestavam como evidentes as discrepâncias entre a alta performance das taxas de crescimento do PIB e, opostamente, as parcas e assimétricas condições de vida da população paquistanesa no seu grosso ${ }^{3}$. De salientar que, como veremos adiante, ul Haq, se veio a encontrar depois entre os impulsionadores do Índice de Desenvolvimento Humano (IDH), cálculo que aglutina a dimensão da educação e a da saúde à dimensão da riqueza dos estados com o intuito de tentar medir o nível de desenvolvimento dos estados.

Por conseguinte, neste trabalho discutiremos alguns índices que, utilizando mais do que o PIB, intentam, declaradamente, comensurar realidades multidimensionais e complexas concernentes ao desenvolvimento dos estados. Estes índices procuram gizar uma análise detalhada, em diferentes prismas, de vários conjuntos de países e,

\footnotetext{
${ }^{1}$ Disponível em http://www.stiglitz-sen-fitoussi.fr/documents/rapport_anglais.pdf

${ }^{2} \mathrm{O}$ sítio Web: http://www.bhutanstudies.org.bt/

${ }^{3}$ Ver a propósito, a caixa 1.1 do RDH de 2010: De Karachi à Sorbonne-Mahbub ul Haq e a ideia do desenvolvimento humano.
} 
permitem ainda comparações entre os países, realçando, sinteticamente, alguns aspectos metodológicos bem como a panóplia de variáveis que os originam.

A montante dos indicadores em estudo encontram-se organizações internacionais que, com distintos campos de aç̧ão, promovem índices com diversas vocações. Então, o Programa das Nações Unidas para o Desenvolvimento (PNUD), , com o Índice de Desenvolvimento Humano (IDH), o Índice de Desenvolvimento Humano Ajustado À Desigualdade (IDHAD) o Índice de Desigualdade de Género (IDG) e o Índice de Pobreza Multidimensional (IPM), enfoca a temática do desenvolvimento humano. O Center for Global Development (CGD), propondo o Índice de Compromisso com Desenvolvimento (ICD) , aborda, igualmente, questões relacionadas com o desenvolvimento, aspirando analisar a questão da Ajuda Pública ao Desenvolvimento (APD) dos países ricos. A Fundação Mo-Ibrahim (FMI) , com o Índice Ibrahim de Governação Africana (IIGA), declara pretender avaliar a qualidade da governação de uma série de países africanos. Finalmente, o Fórum Económico Mundial (FEM), erguendo o Índice de Competitividade Global (ICG), tenta inquirir tanto sobre os níveis de competitividade dos estados, como sobre a medida em que um conjunto de factores potenciam tais níveis competitividade.

\section{2. Índices}

PNUD : Índice de Desenvolvimento Humano, do Índice de Pobreza Multidimensional, do IDH Ajustado à Desigualdade (IDHAD) e do Índice de Desigualdade de Género (IDG)

\section{A - Índice de Desenvolvimento Humano (IDH)}

O IDH surge do trabalho de uma equipa de pensadores sobre as questões de desenvolvimento, da qual constavam os economistas Mahbud u-Haq e Amartya Sen, que elaborou o primeiro Relatório de Desenvolvimento Humano (RDH). Esta equipa, insatisfeita com os utensílios de medição do grau de desenvolvimento económico dos países, na medida em que estes assentavam fundamentalmente sobre critérios estritamente quantitativos, directamente relacionados com os níveis de crescimento alcançados, propôs uma medida alternativa mais ampla, que rivalizasse com o Produto Interno Bruto per capita (PIBpc), o indicador do rendimento nacional dos países eleito pelo mainstream. Colocando as pessoas como a verdadeira riqueza das nações, o primeiro RDH lança o Índice de Desenvolvimento Humano (IDH) em 1990.

Assim, o IDH, para além da dimensão da riqueza dos estados, representada no PIBpc, inclui também duas outras grandezas e com idêntica ponderação, a da esperança média de vida e a da alfabetização.

A produção anual do RDH é da responsabilidade do Programa das Nações Unidas Para o Desenvolvimento (PNUD), http://www.undp.org/. Criado em 1965, vinte anos após a fundação da Organização da Nações Unidas (ONU), com sede em Nova lorque, é a maior agência da ONU de apoio e investimento no desenvolvimento humano a nível global. Os principais objectivos do PNUD são: 
a) a salvaguarda dos mecanismos de cooperação internacional para se alcançar o desenvolvimento humano sustentável;

b) o reforço do papel da ONU, dotando-a de coesão e de consistência no caminho do desenvolvimento humano;

c) canalizar recursos no sentido de atingir um conjunto de objectivos de desenvolvimento humano, entre os quais, a erradicação da pobreza, a preservação ambiental, a criação de emprego e questões de igualdade de género.

O RDH e o IDH estão ambos disponíveis na internet no sítio http://hdr.undp.org.

Em 2010, celebrando 20 anos após o lançamento do primeiro RDH, o PNUD propôs uma nova metodologia de análise como forma de responder às complexidades emergentes dos processos de desenvolvimento humano.

Assumindo a importância dos debates em torno das diversas construções do conceito de desenvolvimento, das suas múltiplas medidas e das suas implicações políticas e institucionais, no RDH de 2010 lê-se:

... reafirmamos o conceito do desenvolvimento humano, sublinhando a sustentabilidade, a igualdade e a capacitação. O objectivo é compreender os padrões do desenvolvimento humano e os modos como as sociedades permitem que as pessoas tenham a vida a que dão valor e as habilitam para tal. Esta é a melhor forma de pensar acerca do progresso humano.

Neste novo RDH, emergem algumas inovações metodológicas e três novos índices: Índice de Pobreza Multidimensional (IPM), IDH Ajustado à Desigualdade (IDHAD) e Índice de Desigualdade de Género (IDG).

$\mathrm{O} I \mathrm{IDH}$, sendo uma tentativa de cômputo sintetizado do desenvolvimento humano, intenta averiguar as realizações médias de um determinado país em três dimensões básicas concernentes ao desenvolvimento humano:

1) a da vida longa e saudável;

2) a do conhecimento;

3) a de um padrão de vida digno.

Por sua vez, as dimensões referidas concretizam-se em quatro indicadores. O indicador da esperança de vida à nascença remete para a primeira dimensão, os da média de anos de escolaridade e dos anos de escolaridade esperados para a segunda e, por fim, o Rendimento Nacional Bruto per capita (RNBpc) para a terceira, a que se propõe ilustrar um padrão de vida digno. O RNBpc, que é obtido somando ao PIBpc o fluxo líquido de rendimentos primários com o resto do mundo, é assente na ideia de que a riqueza produzida num país é cada vez menos coincidente com a riqueza que efectivamente permanece num país, logo, o RNBpc sub-roga no presente ano o PIBpc (utilizado até 2009) enquanto o indicador por excelência do desempenho económico dos estados.

Para o cálculo do IDH é necessária a criação de índices de dimensão, isto é, sub-índices, para cada uma das três dimensões, sendo que tais sub-índices são depois incorporados num único índice, o IDH, que atinge valores compreendidos no intervalo entre 0 e 1 . Representando este a média geométrica dos três índices de dimensão mencionados, há que ajustar cada um deles, transformando os indicadores das dimensões em sub-índices cujos valores estejam contidos estritamente no intervalo de 0 a 1 . A fórmula utilizada para o efeito é a seguinte:

Índice de $\operatorname{dim}$ ensão $=\frac{(\text { valor observado }- \text { valor mínimo })}{(\text { valor mínimo }- \text { valor máximo })}$ 
Assim, o valor máximo remete para o valor máximo efectivamente verificado, entre 1980 e 2010, no conjunto dos estados, no caso dos 83.2 anos na esperança média de vida, 13,2 e 20,6 anos, respectivamente, para a média de anos de escolaridade e para os anos de escolaridade esperados (0,951 no caso do índice de educação) e, por fim, 108.211 PPC USD no que ao índice do RNBpc diz respeito. Por outro lado, o valor mínimo corresponde aos valores de subsistência, ou seja, aos zeros naturais dos indicadores, isto é, 20 anos no caso do indicador da dimensão da esperança média de vida, 0 anos no caso dos dois indicadores respeitantes ao conhecimento e 163 PPC USD no caso do indicador concernente à dimensão um padrão de vida digno, o RNBpc.

O IDH é a média geométrica dos três índices de dimensão, ou seja o seu valor resulta da seguinte fórmula:

$$
I D H=\sqrt[3]{\left(I_{V i d a} \times I_{\text {Educação }} \times I_{\operatorname{Re} n \text { dimento }}\right)}
$$

Uma das inovações metodológicas do IDH de 2010 é a da aceitação da média geométrica. Porque até 2010, o IDH era o índice resultante da média aritmética dos índices de dimensão. A grande vantagem da média geométrica é a de, ao penalizar mais os valores extremos, implicar a não substituibilidade perfeita entre as três dimensões. Assim, produzindo por si só valores mais baixos de IDH, um Estado que revele uma das dimensões significativamente mais fraca do que as restantes será penalizado, vendo assim a sua pontuação deteriorar-se.

O caso da China serve como exemplo prático de como calcular o IDH:

Arcando os seguintes valores:

\begin{tabular}{|lc|}
\hline Indicador & Valor \\
\hline Esperança média de vida (anos) & 73,5 \\
\hline Média de anos de escolaridade & 7,5 \\
\hline Anos de escolaridade esperados & 11,4 \\
\hline RNB per capita & 7.263 \\
\hline
\end{tabular}

Sintetizando os limites para as dimensões:

\begin{tabular}{|lll|}
\hline Dimensão & Máximo & Mínimo \\
\hline $\begin{array}{l}\text { Esperança de vida } \\
\text { Média de anos de }\end{array}$ & 83,2 & 20,0 \\
escolaridade & & 0 \\
\hline $\begin{array}{l}\text { Anos de escolaridade } \\
\text { esperados }\end{array}$ & 20,6 & 0 \\
\hline $\begin{array}{l}\text { Índice de educação } \\
\text { combinado }\end{array}$ & 0,951 & 0 \\
\hline
\end{tabular}


Cálculo do índice de dimensão da esperança de vida:

$$
I_{\text {Vida }}=\frac{73,5-20}{83,2-20}=0,847
$$

Cálculo do índice de dimensão da educação:

$$
\begin{aligned}
& I_{\text {Média anos escolaridade }}=\frac{7,5-0}{13,2-0}=0,568 \\
& I_{\text {Anos escolaridade esperados }}=\frac{11,4-0}{20,6-0}=0,553 \\
& I_{\text {Educcạ̃o }}=\frac{\sqrt{0,568 \times 0,553}-0}{0,951-0}=0,589
\end{aligned}
$$

Cálculo do índice de dimensão do rendimento:

$I_{\text {Rendimento }}=\frac{\ln (726.3)-\ln (163)}{\ln (108.211)-\ln (163)}=0,584$

Cálculo do IDH:

$I D H=\sqrt[3]{0,847 \times 0,589 \times 0,584}=0,663$

Uma análise que intenta sintetizar dimensões complexas, multidimensionais e qualitativas num indicador quantitativo e universal será sempre, no mínimo, redutora. Desta forma, desprovida de capacidade explicativa plena dos fenómenos, parte dos esforços têm passado pela extensão das variáveis em estudos, bem como do quadro teórico no qual estas emergem no sentido de aprimorar o poder elucidativo dos instrumentos de medição do desenvolvimento humano.

O lançamento de três novos índices em 2010 é um caminho encontrado para melhorar o entendimento sobre o desenvolvimento humano a nível global. : o Índice de Pobreza Multidimensional (IMP), IDH ajustado à desigualdade (IDHAD), e o Índice de desigualdade de género (IDG). O RDH de 2010 lança também novas pistas quanto a preocupações, desejos e anseios de futuros RDH's nomeadamente no que toca a indicadores de capacitação e a indicadores de sustentabilidade ambiental, de segurança, de bem estar e de trabalho digno humanos.

\section{B - O Índice de Pobreza Multidimensional (IPM)}

Em 1997 surge o Índice de Pobreza Humana (IPH) no RDH para responder à necessidade de avaliar as conjunturas de pobreza e de privação multidimensionais com o acesso à saúde, nutrição ou habitação, enquanto situações de entrave ao desenvolvimento humano principalmente ao nível dos Estados do hemisfério sul. 
Uma das limitações do IPH era a de apenas realçar privações agregadas, nas três dimensões do IDH, não quantificando, pelo contrário, privações conjuntas, isto é, o número de indivíduos particulares, de agregados familiares, de grupos afectados por situações de pobreza e privações, que se manifestam frequentemente sobrepostas.

O novo índice que surge em 2010, o IPM, procura superar as limitações do seu antecessor, o IPH, ao procurar computar tanto o número e pessoas que são pobres multidimensionalmente como a intensidade da sua pobreza. $O$ IPM é definido segundo dez indicadores, concorrendo cada um deles de forma idêntica para a sua respectiva dimensão. São três as dimensões: saúde, educação e padrão de vida.

Para a dimensão da sáude contam os indicadores referentes à (1) taxa de mortalidade infantil e da (2) nutrição. Para a dimensão da educação, os indicadores dos (3) anos de escolaridade e do (4) número de crianças matriculadas. Finalmente, para a dimensão do dimensão do padrão de vida, concorrem 6 indicadores: (5) o acesso a electricidade; (6) o acesso a água potável limpa; (7) o acesso a saneamento apropriado; (8) o acesso a combustível para cozinhar; (9) o acesso a uma casa com pavimento de terra; (10) e, não tendo carro, a propriedade, no máximo, de dois dos seguintes bens: bicicleta, mota, rádio, frigorifico, telefone e televisão.

Metodologicamente, o IPM resulta do produto de duas medidas. A primeira é a da taxa multidimensional da contagem de pessoas e a segunda é a intensidade/amplitude da pobreza.

Assim, cada uma das três dimensões concorre com uma ponderação de $1 / 3$, e, para cada dimensão os respectivos indicadores possuem igual peso. Assim, no caso da saúde e da educação, com dois indicadores cada, esses indicadores valem $5 / 3$ e, no que ao padrão de vida digno se refere, cada um dos seus seis indicadores concorre com 5/9. A soma dos dez indicadores (5/3+5/3+5/3+5/3+5/9+5/9+5/9+5/9+5/9+5/9) é igual a 1.

Para cada família, efectua-se o somatório das respectivas privações multiplicadas pelo seu peso, isto é, a pontuação de privação ponderada $c$, e, no caso do resultado final ser superior a 3 a família é encarada como pobre. Se o resultado estiver compreendido no intervalo entre 2 e 3, então, a família é considerada vulnerável, isto é, em risco de pobreza multidimensional.

Assim, no sentido de apurar a taxa multidimensional de contagem de pessoas, que é, simplesmente, a proporção da população que é multidimensionalmente pobre, aplica-se o rácio entre o número de pessoas consideradas multidimensionalmente pobres e o número total de indivíduos, assim $H=\frac{q}{n}$,

Com $H$ a representar o proporção de pessoas multidimensionalmente pobres, $q_{0}$ número de indivíduos do conjunto das famílias cuja pontuação de privação ponderada, $c$, é superior a 3, logo, que é, efectivamente, pobre e, por fim, $n$ a população total.

Doutro ponto de vista, a intensidade da pobreza, $A$, expressa a percentagem de indicadores nos quais a pessoa pobre média sofre privações, remetendo, assim, para a relação entre o número de privações ponderadas, $c$, sentidas realmente pelo conjunto das pessoas multidimensionalmente pobres, $q$, e o conjunto total das privações potenciais do total das pessoas multidimensionalmente pobres, ou seja, a relação entre o número médio de pessoas que 
sofrem privações e o numero total de indicadores componentes considerados. A fórmula utilizada é a abaixo retratada:

$A=\frac{\sum_{1}^{q} c}{q \times d}$

Em suma, para calcular o IPM, é suficiente efectuar o produto entre a percentagem de pessoas pobres ( $H$ ) e a percentagem de indicadores nos quais essas pessoas sofrem privações, entre os 10 indicadores $A$. Na prática, $I P M=A \times H$.

\section{C- $O$ Índice de Desenvolvimento Humano Ajustado à Desigualdade (IDHAD)}

O IDHAD aparece em 2010 para computar as perdas ao nível do desenvolvimento humano impostas pela existência de desigualdades nacionais em cada uma das três dimensões do IDH. Até agora o IDH, ao apresentar médias, acabava por encobrir desigualdades entre os individuos de um determinado Estado. Em consequência, os níveis de desigualdade social no seio de uma nação em nada influem na sua pontuação global ao nível do IDH.

O IDHAD, calculado para um conjunto de 139 países, repercute as desigualdades ao nível das dimensões do IDH, diminuindo os seus valores conforme o nível de desigualdade verificado num certo país em cada uma das três dimensões.

Por conseguinte, no limite, o IDHAD assume valores iguais aos do IDH se um país for completamente igualitário no que a cada uma das três dimensões diz respeito, diminuindo à medida que as desigualdades vão crescendo. Logo, o papel fundamental do IDHAD é o de relegar o IDH para um índice potencial, coerente com uma hipotética, e até à data nunca descoberta, igualdade máxima entre os indivíduos.

Do ponto de vista metodológico os passos para calcular o IDHAD são três.

A primeira etapa é a da medição da desigualdade. Assim, empregando para o efeito contributos teóricos acerca da problemática das desigualdades introduzidos por Atkinson, em particular parâmetros de aversão à desigualdade, a medida de desigualdade proposta é a seguinte:

$A=1-\frac{g}{\mu}$

que, intuitivamente, equivale a

$A_{X}=1-\frac{\sqrt[n]{X_{1} \times X_{2} \times \ldots \times X_{n}}}{\bar{X}}, \mathrm{com}$

$A_{\text {a representar a medida de desigualdade e com } g}$ (e $\sqrt[n]{X_{1} \times X_{2} \times \ldots \times X_{n}}$ ) e ${ }^{\mu}$ (e $\bar{X}$ ), respectivamente, a remeterem para a média geométrica e para a média aritmética da distribuição em questão. Assim, conforme discutido no presente texto, a média geométrica traduz-se em valores mais baixos em comparação com a média aritmética, sendo que, à medida que as desigualdades na distribuição aumentam a primeira diminui. Desta feita, o 
rácio $\mu$, compreendido entre 0 e 1 , será igual a 1 em caso de igualdade máxima entre os indivíduos, numa dada dimensão e, opostamente, tenderá para 0 em caso de desigualdade absoluta.

O segundo passo é o de, empregando para o efeito a medida de desigualdade acima mencionada, ajustar os índices de dimensão à desigualdade.

A salientar que, se para ajustar a realização média de cada dimensão basta apenas multiplicar o valor da média aritmética, $\bar{X}$, por $\left(1-A_{X}\right)$, obtendo, deste modo, a média geométrica, então, seguindo a mesma linha de raciocínio, para obter os três índices de dimensão, $I_{I_{X}}$, ajustados à desigualdade há que multiplicar, cada um dos três índices de dimensão do IDH, $I_{X}$, por $\left(1-A_{X}\right)$. Como evidencia a formula abaixo:

$I_{I_{X}}=\left(1-A_{X}\right) \times I_{X}$.

Uma singularidade que nos parece pertinente apontar de momento é a de que, no que ao índice da dimensão

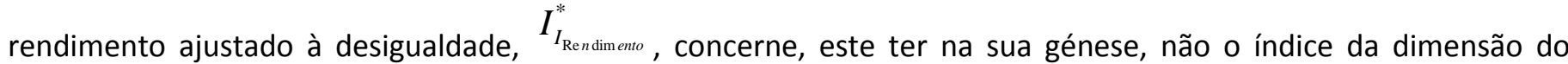
logaritmo do rendimento, mas sim o índice de RNBpc não registado, linear, $I_{\mathrm{Ren} \text { dimento }}^{*}$. Os autores sustentam quanto a esta ocorrência o facto de que deste modo o IDHAD incorporar os efeitos das desigualdades, ao nível do rendimento, na sua plenitude máxima.

Finalmente, a terceira e última etapa, como expectável, resume-se ao cálculo efectivo do IDHAD, fazendo uso do nexo da panóplia de fórmulas em cima retratadas.

Assim, tal como o IDH, o IDHAD é a média geométrica dos três índices de dimensão previamente ajustados, logo, sensíveis à desigualdade.

Assim, em primeiro lugar, calcula-se o IDHAD empregando para tal o índice do rendimento não registado, ou seja, o IDHAD*. Segundo a fórmula seguinte:

IDHAD $D^{*}=\sqrt[3]{I_{I_{\text {Vida }}} \times I_{I_{\text {Educazăoo }}} \times I_{I_{\text {Ren ndimento }}^{*}}^{*}}=$
$=\sqrt[3]{\left(1-A_{\text {Vida }}\right) \times I_{\text {Vida }} \times\left(1-A_{\text {Educaşão }}\right) \times I_{\text {Educaşãoo }}\left(1-A_{\text {Rendimento }}\right) \times I_{\text {Rendimento }}^{*}}$

Bem como o IDH fundado, igualmente, no índice do rendimento não registado, o IDH*, que, recordamos, é o valor do IDHAD* numa situação de igualitarismo primário nas três dimensões, ou seja,

$I D H=\sqrt[3]{I_{\text {Vida }} \times I_{\text {Educação }} \times I_{\text {Rendimento }}^{*}}$

Realçando o intuitivo, caso desejemos mensurar a perda, em percentagem, no IDH*, basta empregar a seguinte equação:

Perda $=\frac{I D H^{*}-I D H A D^{*}}{I D H^{*}}=1-\frac{I D H A D^{*}}{I D H^{*}}=$
$=1-\sqrt[3]{\left(1-A_{\text {Vida }}\right) \times\left(1-A_{\text {Educaşão }}\right) \times\left(1-A_{\text {Rendimento }}\right)}$ 
Em conclusão, para calcular o IDHAD, partindo da hipótese de que a perda, em percentagem, no que à dimensão do rendimento se refere, assume os mesmos valores quer se empregue o rendimento médio ou o seu logaritmo, basta seguir a equação:

$I D H A D=\left(\frac{I D H A D^{*}}{I D H^{*}}\right) \times I D H \Leftrightarrow$

$I D H A D=\sqrt[3]{\left(1-A_{\text {Vida }}\right) \times\left(1-A_{\text {Educą̧ão }}\right) \times\left(1-A_{\text {Rendimento }}\right)} \times I D H$

\section{D - $O$ Índice de Desigualdade de Género (IDG)}

O IDG, que abrange 138 países, pretende possibilitar uma análise quantitativa das desigualdades ao nível do género.

O reconhecimento de que as desigualdades ao nível de género representa uma das principais obstruções ao desenvolvimento humano, levou há 15 anos atrás à elaboração de dois índices: o Índice de Desenvolvimento Ajustado ao Género (IDG) e a Medida de Participação segundo o Género (MPG).

A produção do IDG em 2010 teve na sua génese estes dois índices, produzidos pelo RDH de 1995 e é por isso uma evolução dos mesmos, ao responder a um conjunto de críticas lançadas à metodologia adoptada nos dois índices.

O IDG baseia-se em 5 indicadores relacionados com 3 dimensões e cujos valores variam entre 0 e 1 . A dimensão do trabalho inclui o indicador da participação da força de trabalho; a dimensão da capacitação avalia os indicadores da realização educativa e da representação parlamentar e, finalmente, a dimensão da saúde reprodutiva, que remete para os indicadores da fertilidade adolescente e da mortalidade materna.

Do ponto de vista metodológico, o cálculo do IDG obedece a quatro etapas básicas.

Com,

TMM - Taxa de mortalidade materna

TFA - Taxa de fertilidade adolescente

PR - Distribuição dos assentos parlamentares por sexo

ES - Sucesso escolar (ensino secundário e superior)

TPMT - Taxa de participação no mercado de trabalho

Em primeiro lugar, há que agregar as dimensões concernentes ao género feminino e ao género masculino. Assim, pela média geométrica, aglutinam-se os indicadores das dimensões para o grupo das mulheres $G_{F}$ e para o grupo dos homens $G_{M}$, pela seguinte fórmula:

Para as mulheres:

$G_{F}=\sqrt[3]{\left(\frac{1}{T M M} \times \frac{1}{T F A}\right)^{1 / 2} \times\left(P R_{F} \times E S_{F}\right)^{1 / 2} \times T M P T_{F}}$

Para os homens: (0.1) $G_{M}=\sqrt[3]{1 \times\left(P R_{M} \times E S_{M}\right)^{1 / 2} \times T M P T_{M}}$ 
A segunda etapa é a de, empregando a média harmónica das médias geométricas dos dois agregados, $G_{F}$ e $G_{M}$, criar o índice de género distribuído igualitariamente, assim:

$\operatorname{HARM}\left\{G_{F}, G_{M}\right\}=\frac{\left[G_{F}^{-1}+G_{M}^{-1}\right]^{-1}}{2}$

Intermediamente, o terceiro ponto é o cálculo da média geométrica das médias aritméticas de cada indicador, em suma, o padrão de referência ilustrado na equação que se segue:

$G_{\bar{F}, \bar{M}}=\sqrt[3]{\text { Saude } \times \text { Capacitação } \times T P M T}$

Onde,

Saúde $=\frac{\sqrt{\left(\frac{1}{T M M} \times \frac{1}{T F A}\right)}+1}{2}$

Capacitação $=\frac{\left(\sqrt{P R_{F} \times E S_{F}}\right)}{2} \mathrm{e}$

$T P M T=\frac{\left(T M P T_{F}+T M P T_{M}\right)}{2}$

Por fim, a diferença relativa entre o índice de género distribuído equitativamente $H A R M\left\{G_{F}, G_{M}\right\}$ e o padrão de $G$

referência $\bar{F}, \bar{M}$ materializa-se no IDG, ou seja,

$I D G=\frac{G_{\bar{F}, \bar{M}}-H A R M\left\{G_{F}, G_{M}\right\}}{G_{\bar{F}, \bar{M}}} \Leftrightarrow$

$I D G=1-\frac{-H A R M\left\{G_{F}, G_{M}\right\}}{G_{\bar{F}, \bar{M}}}$

\section{E - Fundação Mo Ibrahim: Índice Ibrahim de Governação Africana 2010 (IIGA)}

A Fundação Mo Ibrahim, criada pelo empresário Mo Ibrahim, quer estimular uma liderança africana com dignidade e que permita melhorar as perspectivas económicas e sociais dos povos africanos. Assim, tem quatro grandes objectivos:

1) Promoção do debate sobre a governação a nível mundial, em geral, e nos Estados dos países da região da África Subsariana, em particular, a título de modelo, motivando a criação de parcerias com o mundo empresarial e com a realidade académica;

2) Condecoração dos bons desempenhos ao nível da liderança em África através, por exemplo, da atribuição do prémio Mo Ibrahim para o melhor governante; 
3) Apoio à emergência de futuros lideres no continente africano, concedendo bolsas de estudo e de investigação a jovens promissores;

4) Criação de critérios que permitam aos cidadãos responsabilizar mais convenientemente os seus governantes através de instrumentos como o Índice Ibrahim de Governação Africana (IIGA).

O IIGA (disponível em http://www.moibrahimfoundation.org/pt/section/the-ibrahim-index) é produzido desde 2007 pela Fundação Mo-Ibrahim. Este índice quer promover e estimular o debate sobre a governação em países africanos, responsabilizando assim os governantes perante a sociedade civil, ou seja, os cidadãos, os sindicatos, as empresas e as organizações não governamentais. O principal objectivo do IIGA é monitorizar a classe governante, medir a qualidade e o talento da sua capacidade governativa no fornecimento de bens e serviços económicos, políticos e sociais prestados aos cidadãos.

O IIGA, que quantifica as competências dos responsáveis político-institucionais em 53 Estados africanos, define indicadores para quatro categorias: Segurança e Estado de Direito, Participação e Direitos do Homem, Desenvolvimento Económico e Sustentável e Desenvolvimento Humano.

Em cada uma destas categorias são incluídas treze subcategorias que, por sua vez correspondem a 88 variáveis distintas (ver Anexo 1).

A produção do IIGA beneficia do acesso a um conjunto de dados/informação fornecidos por 23 instituições internacionais externas, factor que contribui para uma maior associação deste índice a um maior grau de imparcialidade e de credibilidade. A seguinte hiperligação remete para a descrição dos indicadores e respectivas origens dos dados: http://www.moibrahimfoundation.org/en/media/get/20101008 portuguese-indicator-recordsheets-pdf.pdf.

O IIGA responde a uma escala de 0 a 100, uma vez finalizado o processo de recolha de informação, os dados são redimensionados de modo a serem compativelmente mensuráveis com o referido intervalo de valores.

O método empregue é muito semelhante ao do aplicado ao Índice de Desenvolvimento Humano (IDH), e é designado pela Fundação Mo-Ibrahim de método Min-Máx e a formula respectiva é a seguinte:

$\left(\frac{X_{t}-\operatorname{Min}(X)}{\operatorname{Máx}(X)-\operatorname{Min}(X)}\right) \times 100$

Com $X_{t}$ a representar o valor efectivamente observado num determinado ano e num pais concreto, enquanto $\operatorname{Min}(X)$ e $\operatorname{Máx}(X)$ remetem, respectivamente, para o valor mínimo e para o valor máximo verificados no conjunto dos países.

Os índices de qualquer uma das treze categorias são auferidos calculando a média de cada um dos indicadores que Ihe tocam directamente, enquanto os índices de cada uma das quatro categorias se obtêm aplicando novamente a média das subcategorias que the concernem. A pontuação de cada país é o resultado da média das suas quatro categorias.

Uma situação a destacar é a de que todo o tipo de índices e indicadores, essencialmente devido a questões de extrapolação e estimação de dados em falta, comportam uma determinada margem de erro. Tal erro aumenta na medida em que ocorre um elevado grau de dispersão dos próprios dados. Deste modo, no que ao IIGA diz respeito, a 
margem de erro média nas pontuações globais dos países é de sensivelmente 8 pontos. Tal facto sugere que, por um lado, as comparações entre países com diferenças pontuais pouco significativas deverá ser sempre feita com cautela, e por outro lado, a mesma prudência deverá ser tida em conta quando se trata de confrontações ao longo do tempo. Um dado a salientar neste índice é a ausência do indicator e categoria pobreza apesar da sua importância para avaliação do sucesso de políticas governamentais., Os autores do IIAG sugerem que não existe uma cobertura de dados suficientemente regular e exaustiva para que seja possível incluir a dimensão da pobreza.

\section{F- Instituto Legatum: Índice de Prosperidade Legatum}

O Índice de Prosperidade (IPL) tem como objectivo incentivar não só os agentes políticos, como também as comunidades académicas, e ainda, em certa medida, as sociedades civis, a adoptarem uma perspectiva do conceito de prosperidade não circunscrita ao conceito de riqueza material. Assim, o IPL coloca enquanto cerne do conceito de prosperidade a interacção de factores relacionados com o crescimento económico e com o bem estar dos cidadãos.

O IPL produz um relatório anual desde 2006 que conclui que a) os países que maior prosperidade alcançam são aqueles que têm democracias empreendedoras; b) têm mais hipóteses de progredir aqueles países que compreendem o conceito de prosperidade enquanto meta-numérico e c) a uma escala planetária, os rankings de prosperidade têm vindo a sofrer mutações consideráveis.

Existindo alguns índices análogos ao IPL, os autores sustentam, contudo, que parte da necessidade de edificação deste índice se prende com o facto de se entender que este é a única medida de prosperidade relacionada com o rendimento e com o bem estar dos estados, empregando, para tal, diversos conjuntos de indicadores, fundados em informação quantitativa e qualitativa, sobre a riqueza e sobre o bem estar.

O IPL é produzido pelo Legatum Institute ligado ao Legatum Group (LG) que surge no Dubai na década de 90 com o desígnio da promoção do esclarecimento dos investidores a propósito do desenvolvimento sustentável do conjunto da comunidade global.

A LG é uma organização global de investimentos que afecta verbas nos mercados mundiais, isto é, um hedge fund. Da estrutura do $L G$ constam seis instituições, a saber, a Legatum Capital, a Legatum Ventures, o Legatum Center Massachusetts Institute of Technology, a Legatum Foundation, a Prosperity Ladder e o Legatum Institute, cada qual com o seu papel na engrenagem da $L G$, respectivamente, investimentos de carteira, criação de novos activos nos mercados de capitais, ligação com o mundo académico através do incentivo/financiamento de programas de empreendedorismo concebidos no seio do MIT, concessão de bolsas de microcrédito a organizações locais e alocação directa de capital.

O Legatum Institute, o último destes organismos dependentes do LG, trata-se de uma instituição que se autodesigna enquanto promotora e estudiosa de um conceito abrangente da prosperidade global. Na prática, o principal contributo do Legatum Institute para tal ensejo traduz-se na elaboração do Índice de Prosperidade Legatum (IPL), disponível em http://www.prosperity.com .

O IPL procura hierarquizar um conjunto de 110 países, intentando, assim, comensurar os níveis de riqueza e de bem estar verificados nos mesmos, isto é, averiguar em que medida os estados são prósperos. 
Numa perspectiva prática, o IPL é o resultado da média de 8 sub-índices: o da Economia, o do Empreendedorismo e Oportunidades, o da Governação, o da Educação, o Saúde , o da Segurança, o da Liberdade Pessoal e o do Capital Social. Assim, empregando 89 variáveis no conjunto dos 8 sub-índices, procura inquirir a magnitude do efeito que tais variáveis exercem sobre cada um dos sub-índices.

\section{http://www.prosperity.com/downloads/2010ProsperitylndexTechnicalAppendix.pdf}

Cada sub-índice dá-nos uma dupla informação: em que medida é que as variáveis concorrem para o rendimento e em que medida é que as variáveis competem para o bem estar. Através de sucessivas regressões, procura-se determinar o nível de significância que cada variável tem em cada sub-índice, sendo que a decorrente informação estatística nos indica o grau de correlação entre um maior rendimento e um maior bem estar.

Com efeito, em cada um dos sub-índices estão patentes duas regressões, uma cuja variável dependente é o rendimento, e outra cuja variável explicada é o bem-estar subjectivo, regressões essas que estimam a ponderação de cada variável nos respectivos sub-índices.

Logo, considerando não só que as variáveis se encontram em diferentes escalas de grandeza, bem como o facto de que os sub-índices se encontram confinados a uma escala em que a média é 0 , as variáveis têm que ser estandardizadas, para que se possa proceder a uma comparação entre as ditas. Para tal, utiliza-se a seguinte fórmula:

$$
X_{E s \tan \text { dardizada }}=\frac{X-\bar{X}}{\sigma_{X}}
$$

Com,

$X$ - valor da variável, $\bar{X}$ - o valor médio e ${ }^{\sigma_{X}}$ - o desvio padrão de $X$

$X_{E s \tan \text { dardizada }}=\frac{X-\bar{X}}{\sigma_{X}}$

\section{G - Center for Global Development: Índice de Compromisso com Desenvolvimento (ICD)}

O Índice de Compromisso com Desenvolvimento (ICD), em parceria com a revista Foreign Policy, é produzido anualmente desde 2003, e quantifica a importância do impacto de uma série de políticas públicas para a cooperação internacional assumidas por 22 países desenvolvidos (disponível em http://www.cgdev.org/section/initiatives/ active/cdi/.

O ICD reconhece que os contributos para a redução da pobreza dos países em desenvolvimento não se esgota na Ajuda Pública ao Desenvolvimento (APD), i.e., ajuda externa, e por isso avalia, pontua e classifica num ranking o compromisso com o desenvolvimento destes 22 países em sete grandes áreas-chave: (1) APD; (2) Comércio: (3) Investimento; (4) Migração; (5) Ambiente; (6) Segurança; (7) Tecnologia.

Este ranking não pretende apenas estabelecer uma hierarquização de quem melhor se comporta na cooperação internacional mas também chamar a atenção dos media e da sociedade civil para aspectos como;

a) a forma multifacetada como as acções dos países ricos afectam o desenvolvimento; 
b) a forma como as políticas de APD definidas pelos países desenvolvidos afectam o desenvolvimento dos países menos ricos;

c) a forma como o estímulo da actividade de recolha e tratamento de dados pode influenciar as políticas públicas munidas de informação mais detalhadas;

d) e a forma como se podem pensar e arquitectar novas maneiras de medir o desenvolvimento.

O ICD é produzido pelo, o think tank Center for Global Development (CGD) fundado em 2001. O CGD é uma organização independente do poder politico sem fins lucrativos cujo móbil é o da promoção do debate em torno da redução da pobreza e das desigualdades globais. (http://www.cgdev.org/)

O CGD procura envolver não só as classes políticas e legisladoras, em particular, como também o público, no debate em torno da compromisso de garantir uma melhoria das condições de vida e das perspectivas de desenvolvimento dos países menos ricos. Assim, o CGD procura influenciar as opções de política externa dos países desenvolvidos e as linhas orientadoras de organizações multilaterais como o Banco Mundial, o Fundo Monetário Internacional ou a Organização Mundial do Comércio, em relação por exemplo a questões como o reescalonamento das dívidas externas diz respeito.

O CGD desenvolve pesquisa e investigação em torno de vários tópicos, como a eficácia da ajuda, a educação, a saúde, a globalização, a migração, o comércio, entre outros temas macro. Do ponto de vista micro, são igualmente abordadas várias temáticas, como por exemplo, a do VIH/SIDA e a da demografia. Desta forma, é reforçada a ideia de que pesquisas empíricas rigorosas são veículos de criação de novas ideias, e que estas procuram promover práticas alternativas de políticas inovadoras para melhorar a performance da economia global, no conjunto, e das economias mais vulneráveis, no específico.

Em relação a cada uma das áreas-chave:

1) Na questão da APD os autores alertam para a importância de ser feita uma distinção entre ajuda em termos absolutos, quantitativos, isto é em quantidade, da qualidade da ajuda - a eficácia da ajuda. Assim, antes de mais, as verbas implicadas são expressas em termos relativos em percentagem do PIB. Por outro lado, é sustentada a ideia de que ajuda dirigida a estados mais corruptos e com um estado de direito mais enfraquecido deve ser penalizada, logo, deve contribuir menos para a pontuação da dimensão da ajuda. Um exemplo é o da comparação entre a cotação da ajuda quando o seu destino é o Iraque e a cotação quando o país auxiliado é o Malawi, pois enquanto a primeira é cotada a 15 cêntimos de USD, a segunda é cotada a 89 cêntimos da mesma unidade monetária. Do mesmo modo, a ajuda que impõe contrapartidas comerciais também são penalizados. De salientar que tais critérios exercem um certo efeito penalizador nas pontuações globais dos Estados, evidente nos casos dos dos EUA e do Japão. O contrário, maior pontuação, é patente nos casos dos Estados Escandinavos e Holanda.

2) Partindo do pressuposto liberal de que barreiras ao comércio, por parte dos países desenvolvidos, contribuem quebras nas taxas de crescimento dos países desenvolvidos e, consequentemente, para um aumento do desemprego nesses países, O ICD, na sua componente do comércio, penaliza os países desenvolvidos que erguem barreiras comerciais, em particular, os impostos sobre a importação de bens dos países pobres e subsídios aos agricultores dos países ricos. 
3) O investimento (directo estrangeiro) é outra das componentes do ICD. Nesta área-chave, sem deixar de ter em conta os benefícios (reforço da capacidade produtiva), mas também os riscos (construção, por exemplo, de "elefantes brancos") do investimento (directo estrangeiro), o ICD recompensa as políticas que promovam o investimento em projectos incitadores do desenvolvimento nos países menos ricos e penaliza aquelas que estimulem projectos associados ao aumento dos índices de corrupção e sua consequente instabilidade.

4) No caso da migração, O ICD atribui pontuações às políticas dirigidas ao grau de abertura quanto à recepção de imigrantes qualificados e não qualificados, atribuindo maior ponderação aos últimos. Outro dos factores que concorre para a componente em questão é o da abertura quanto ao acolhimento de jovens estudantes e de refugiados provenientes de países em vias de desenvolvimento.

5) Em relação ao ambiente, o ICD procura reconhecer os perigos inerentes à sobreexploração dos recursos naturais comuns globais, emissões de gases responsáveis pelos efeitos de estufa, ou a utilização de combustíveis fosseis. O ICD pontua favoravelmente as políticas que apoiem uma maior sustentabilidade ambiental. .

6) Na segurança são evidenciadas duas questões fundamentais, uma que contribui de forma positiva e outra de sentido oposto. No primeiro caso, concorrem as contribuições financeiras e de pessoal para operações de paz ou intervenções humanitárias aprovadas pelos concelhos de segurança da ONU ou da NATO. O aspecto negativo é o que se prende com a exportação de armas direccionadas a países antidemocráticos.

7) Finalmente, o ICD recompensa políticas tecnológicas de estímulo e apoio à criação e difusão de inovações criadoras de valor nos países menos ricos e subsídios dos governos à investigação . De relevar o facto de que certo tipo de direitos de propriedade intelectuais e patentes, por inibirem de uma forma perversa os fluxos internacionais de inovações, designadamente os que se prendem com medicamentos, serem desincentivadas.

Em termos de metodologia, sendo o ICD resultado da média simples de cada uma das sete partes, isto tendo em conta que para atingir essa média se procedeu a uma estandartização de cada um dos sete indíces, e que tal estandartização foi feita em consonância com uma escala cuja média é 5, então cada uma das sete dimensões concorre com igual ponderação para o resultado final.

De frisar o facto de serem empregues dezenas de indicadores no índice, que, por seu turno, contribuem assimetricamente para a componente onde se concretizam. Assim, uma etapa importante no processo de construção do ICD é o da ponderação da importância relativa que cada indicador deve ter na sua respectiva componente, em coerência com as idiossincrasias das componentes individuais .

Um detalhe metodológico é o de que, até ao ano de 2006, cada uma das sete dimensões particulares do índice estava sujeita a uma escala de 0 a 10. O mesmo não acontece no CID de 2010. Com a obrigatoriedade da média, para cada uma componente ser igual a 5, um pais hipotético, três vezes melhor do que a média, terá uma pontuação de 15 valores. Tal alteração metodológica facilita comparações entre países no que a cada dimensão concerne e, mais importante, de certa forma, confere uma maior solidez aos resultados. Deste modo, até 2006, se a média de uma 
componente, por exemplo a da ajuda, fosse o dobro de outra, a da tecnologia, seja 8 e 4, um país poderia obter uma pontuação de 6 e 5 o que indiciaria, falaciosamente, que a sua performance ao nível da ajuda seria superior à do nível da tecnologia.

\section{H- Fórum Económico Mundial: Índice de Competitividade Global (ICG)}

O Índice de Competitividade Global (ICG) dispõe os países em função dos seus níveis de competitividade e faz parte do Relatório de Competitividade Global (RCG), disponível em http://www3.weforum.org/docs/WEF GlobalCompetitivenessReport 2010-11.pdf.

O RCG é publicado anualmente desde 1979. Analisa e avalia em detalhe a competitividade de uma série de Estados mundiais em que se entende por competitividade: o conjunto de instituições, das políticas e dos factores que determinam o nível de produtividade um país.

O ICG e o RCG dão-nos a conhecer o conjunto de pontos fortes e e fracos, em matéria de competitividade, dos países. Para o Fórum, o RCG e ICG servem para facilitar o entendimento dos factores nucleares determinantes do crescimento económico, contribuindo, desta forma, para um melhoramento das reformas políticas, económicas e institucionais.

Empregando dados oriundos de organismos oficiais e de instituições supranacionais, entre os quais o Fundo Monetário Internacional (FMI) , o Banco Mundial (BM), a Organização das Nações Unidas (ONU) e a Organização para a Cooperação e Desenvolvimento Económico (OCDE), o ICG tem, na sua génese, mais de uma centena de indicadores (116) que possibilitam a contemplação de um número vasto de economias (139). Desta forma, o ICG atesta-se enquanto um índice abrangente em comparação com os seus homólogos.

Por outro lado, os 116 indicadores referidos concretizam-se em 12 pilares de competitividade, que, por sua vez, representam áreas tidas enquanto determinantes de competitividade e que, por seu turno, erguem três sub-índices, o dos requerimentos básicos, o dos factores potenciadores de eficiência e o dos factores de inovação e sofisticação. Naturalmente, o ICG é a média dos três sub-índices.

Os doze pilares (ver Anexo 3) são os seguintes: I - instituições, II - infra-estruturas, III - ambiente macroeconómico, IV - saúde e educação primária, V - educação superior e formação, VI - eficiência dos mercados, VII - eficiência dos mercados de trabalho, VIII - eficiência dos mercados financeiros, IX - tecnologia disponível, X - dimensão dos mercados internos e externos, XI - sofisticação dos processos de produção e XII - inovação.

O ICG e o RCG são produzidos pelo Fórum Económico Mundial (FEM) fundado em Janeiro de 1971, em Genebra, sob o patrocínio da Comissão Europeia e de várias associações industriais europeias. O (FEM) é uma fundação sem fins lucrativos e é composto por políticos, académicos, jornalistas e empresários. (http://www.weforum.org/)

No ICG e RCG, os países em estudo são igualmente agrupados em três grupos, directamente ligados ao estágio de desenvolvimento das suas economias. Assim, países no primeiro estágio são aqueles menos desenvolvidos, onde predominam o trabalho pouco qualificado parcamente remunerado e o sector primário. Para este primeiro grupo concorrem essencialmente os pilares I, II, III e IV. À medida que um pais se vai tornando mais competitivo, teoricamente, segundo o ICG, dar-se-ão aumentos ao nível salarial e do desenvolvimento, e, em concomitância, do desenvolvimento de processos de produção mais eficientes. Assim, sendo a competitividade baseada numa maior 
educação e formação, os pilares de competitividade mais preponderantes são os V, VI, VII, VIII, IX e X. Por conseguinte, segundo o quadro teórico do qual o ICG emerge, o denominador comum dos países que encetam o terceiro grupo é o de que os factores que determinam os seus níveis de competitividade são essencialmente factores relacionados com a inovação e tecnologia de ponta incorporada nos seus processos produtivos. Desta feita, os pilares de competitividade em relevo são os XI e XII.

O principal critério de afectação dos países a cada um dos três grupos é o nível de PIBpc verificado. Assim, um país com um nível inferior a 2,000 pertencerá ao primeiro grupo, até 9,000 ao segundo e, finalmente, superior a 17,000 ao terceiro conjunto.

Analogamente, os pilares que concorrem para o sub-índice da dimensão dos requerimentos básicos são os I, II, III e IV, para o dos factores potenciadores de eficiência os V, VI, VII, VIII, IX e X e para o dos factores de inovação e sofisticação os XI e XII. De salientar o facto de que, no que às ponderações de cada um dos três sub-índices no ICG diz respeito, estes variam de acordo com o estágio de competitividade em que um pais se encontre.

Utilizando o método econométrico no intuito de aferir as ponderações dos factores que determinam a competitividade duma dada nação, os autores optaram pelas seguintes percentagens, respectivamente para os subíndices dos requerimentos básicos, dos factores potenciadores de eficiência e dos factores de inovação e sofisticação: 60\%, 35\% e 5\%, em países do primeiro grupo; $40 \%$, 50\% e 10\%, em países do segundo grupo e $20 \%, 50 \%$ e $30 \%$, no caso de países pertencentes ao terceiro agregado.

No que toca à escala eleita para expressar as variáveis, a saber, de 1 a 7 , a metodologia que lhe está subjacente é o processo min-max e a fórmula empregue foi a seguinte:

$6 \times \frac{(\text { pontuação do país }- \text { mínimo })}{(\text { máximo }- \text { mínimo })}+7$

Com o mínimo e o máximo a remeterem, respectivamente, para o valor mínimo e máximo observados no conjunto dos estados cobertos pelo ICG.

\section{Conclusão}

Em relação aos índices que estudámos, consideramo-los, em certa medida, satisfatórios, não obstante, entendemos que existe ainda, em seu torno e no seu seio, alguma margem para aperfeiçoamento.

Uma circunstância congratulatória, do ponto de vista metodológico, consiste no facto de que todos os índices estudados, no geral, empregam tanto dados quantitativos como dados qualitativos, isto é, fazem uso de informação subjectiva (como realização de entrevistas e questionários e apuramento de percepções) e, ao mesmo tempo, de informação objectiva (como a análise de agregados macroeconómicos). Tal abordagem, parece-nos, aumenta o poder explicativo dos índices, dotando-os, assim, de uma maior solidez e robustez.

De salientar, por outro lado, a questão da dimensão da sustentabilidade ambiental não concorrer, de forma alguma, para todos os índices. Deste modo, tanto nas contas do IPL como nas do ICG, não cabem indicadores subordinados à temática do meio ambiente. O mesmo não ocorre quanto falamos do IIGA ou do ICD, uma vez que a dimensão do ambiente surge contabilizada, se bem que com maior preponderância no último. Em relação ao IDH (ao IDHAD, ao IPM e ao IDG) constatamos que, pese embora a dimensão ambiental se encontre omitida, o RDH apresenta-nos na 
parte do anexo estatístico, enquanto dimensão do desenvolvimento humano, uma das tabelas, denominada sustentabilidade e vulnerabilidade, que nos fornece dados a propósito desta componente. Porventura, um dos maiores contributos para a diminuição da décalage entre a realidade e os respectivos reflexos dos índices passa pela contabilização da referida dimensão.

De certa forma, um dos pontos fortes, tanto do IDH como do ICG e do IPL, é o da cobertura de um número elevado de países, respectivamente, 169, 139 e 110. Tal facto, na nossa opinião, facilitando uma maior e mais certeira intelecção de agregados de estados com padrões afins, contribui para evidenciar, também, tendências regionais ${ }^{4}$ entre pares e contribui analogamente para elevar o patamar de comparatibilidade entre países.

Por outra via, o IIGA, o único índice sobre a temática da governação que debatemos, abrange um conjunto de 53 países, no entanto, todos do continente africano. Por fim, chamamos a atenção para o CGD que apenas dedica a sua análise a 22 países, segundo os autores, os mais desenvolvidos, deixando de fora, a título de exemplo, qualquer país do denominado grupo dos BRIC e que têm vindo a desempenhar um papel cada vez mais relevante na ajuda ao desenvolvimento.

Outra problemática, a nosso ver, decisiva, é a da pobreza, desigualdades e exclusões sociais. Dado que estas realidades são multidimensionais, multíplices e multipolares, existem, de facto, dificuldades acrescidas no que à sua mensuração diz respeito. Por outro lado, sendo a pobreza, desigualdades e exclusões sociais dos indicadores fundamentais não só do desenvolvimento humano, da felicidade e bem estar dos indivíduos, bem como do sucesso de uma boa governação, cremos, indubitavelmente, estar na presença de uma realidade a ter em conta. Pondo as coisas de outra forma, inclusive do ponto de vista da competitividade entre os estados, do que é que serve à população de um país habitar uma economia perenemente competitiva quando, em concomitância, apresenta elevados níveis de pobreza(s) e de exclusão social?

Assim, constatamos que, no que concerte à questão da pobreza, nenhum índice, à excepção do IPM, a incorpora enquanto uma dimensão. Em relação ao problema das exclusões sociais, este aparece apenas retratado no IIGA, por seu turno, no IPL evidencia-se alguma preocupação, designadamente ao nível dos índices de subnutrição e das liberdades pessoais. Em relação ao IGC apenas remete para questões de saúde e de educação, no entanto, inquere, sobretudo, o modo como estes influem na área dos negócios. De relevar o facto de que, em relação às desigualdades sociais, índice algum aborda tal tema, exceptuando o IDHAD. Mais uma vez chamamos a atenção para a ideia de que embora o IDH não se dedique, por ora, directamente a questões de pobreza e de exclusão social, no seu anexo estatístico, o RDH intenta em abordar tal temática, por exemplo, através das tabelas do trabalho digno, da capacitação ou da segurança humana.

Um dos aspectos positivos do ICG é o de não atribuir as mesmas ponderações a todos os países, embora a destrinça seja feita única e exclusivamente através dos níveis de PIB verificados. Julgamos, assim, que uma das maiores deficiências tanto do IDH (como dos restantes índices) é o tratar todos os países de igual forma. Desta feita, no nosso entender, a questão da analise de países tão diversos, envoltos em conjunturas igualmente dispares, requer uma certa atenção. Por conseguinte, acreditamos que se podem fazer alguns esforços no sentido de melhor adequar os indicadores às especificidades de cada contexto espacio-temporal, geo-político e económico-social.

\footnotetext{
${ }^{4}$ Todos os relatórios abordados dedicam algumas páginas à análise do comportamento das tendências regionais.
} 
Um aspecto importante da matéria em ensaio é o de que os factores que contribuem para o bem estar, para as liberdades, direitos e garantias das populações, para os níveis de desenvolvimento humano, de acordo com o que apontámos do decorrer do texto, são dotados de uma existência e de uma essência multidimensional e complexa. Assim, qualquer tarefa que se resuma a cardinalizar e a condensar em números tal realidade é sempre uma missão espinhosa e redutora.

Por outro lado, como fomos constatando ao longo do presente trabalho, o valor heurístico do PIB é, sem dúvida, vacilante, pois, embora seja um indicador dos níveis actividade económica, tal grandeza, envolta em tamanhas controvérsias, é uma medida pequena e limitada.

Assim, um dos desafios da actualidade, é o do prosseguimento dos trabalhos no sentido de aprimorar indicadores alternativos, com múltiplas incorporações, provenientes de diversas disciplinas científicas, mais qualitativas e ainda quantitativas, objectivas e subjectivas, que, embora não almejem substituir o PIB, complementem este indicador da produção económica e, deste modo, contribuam para um repensar do próprio sistema de contas nacionais.

Frisando um dos aspectos fundamentais, senão o cerne da problemática em questão, enunciamos a (não) existência de cobertura de dados, sobretudo ao nível dos países menos desenvolvidos. Por conseguinte reforçamos a importância do estímulo, do reforço e da consolidação do papel de institutos nacionais de estatísticas à altura dos desafios que evocámos. Não podemos omitir que, em última instância, cálculos que envolvem escassez de dados são cálculos incompletos e, da mesma forma, cálculos incompletos são cálculos que se podem revelar, probabilisticamente falando, enquanto cálculos errados.

Concludentemente, sem a existência de dados e de informação credíveis não são possíveis decisões nem escolhas cabais, nem, tão pouco, é exequível a avaliação e a apreciação de políticas, públicas e privadas, donde, sem escrutínio não há qualquer possibilidade da existência de democracia. 


\section{Bibliografia}

Amaral, J. F. (1996), Política Económica: Metodologia, concepções e instrumentos

de actuação, Lisboa: Edições Cosmos

Dowbor, L. (2006), Democracia Económica - um passeio pelas teorias, São Paulo

Stiglitz, J; Sen, A; Fitoussi, J. P. (2009), Report by the Commission on the Measurement of Economic Performance and Social Progress, http://www.stiglitz-sen-fitoussi.fr/documents/rapport anglais.pdf, 25/01/2011

Centro para o Desenvolvimento Global (2010), http://www.cgdev.org/section/initiatives/ active/cdi/inside, $25 / 01 / 2011$

Fórum Económico Mundial (2010), http://www3.weforum.org/docs/WEF GlobalCompetitivenessReport 201011.pdf, 25/01/2011

Fundação Mo Ibrahim (2010), http://www.moibrahimfoundation.org/pt/section/the-ibrahim-index, 25/01/2011

Instituto Legatum (2010), http://www.prosperity.com/downloads/2010ProsperitylndexFullReport.pdf, 25/01/2011

$\begin{array}{llllll}\text { Programa } & \text { das } & \text { Nações (2010), }\end{array}$

http://hdr.undp.org/en/reports/global/hdr2010/chapters/pt/, 25/01/2011 
Anexo 1: Indicadores Índice Ibrahim de Governação Africana 2010 (IIGA)

\section{Categoria 1 - Segurança e Estado de Direito}

Subcategoria A - Segurança Pessoal

Indicadores: i-Segurança pessoal

$$
\begin{aligned}
& \text { ii - Crime violento } \\
& \text { iii - Agitação pessoal } \\
& \text { iv - Tráfico de seres humanos } \\
& \text { v-Perseguições políticas }
\end{aligned}
$$

Subcategoria B - Estado de Direito

$$
\begin{array}{ll}
\text { Indicadores: } & \text { i-Força da justiça } \\
& \text { ii - Independência judicial } \\
& \text { iii-Defesa da propriedade } \\
& \text { iv-Transferência disciplinada do poder } \\
& \text { v-Sanções }
\end{array}
$$

Subcategoria C - Responsabilização e Corrupção

Indicadores: i-Transferência e corrupção

ii - Responsabilização de responsáveis políticos

iii - Corrupção no governo e funcionários públicos

iv - Processo de abuso de poder

v-Corrupção e burocracia

vi - Responsabilização, transferência e corrupção locais

Subcategoria D - Segurança Nacional

Indicadores: $\quad \mathrm{i}$-Conflito armado interno

$$
\begin{aligned}
& \text { ii - Implicação do governo num conflito armado } \\
& \text { iii - Baixas entre combatentes (civis e militares) } \\
& \text { iv - Baixas entre civis devido a violência direccionada contra civis } \\
& \text { v - Refugiados nacionais } \\
& \text { vi - Pessoas deslocadas internamente } \\
& \text { vii - Tensões internacionais }
\end{aligned}
$$

\section{Categoria 2 - Participação e Direitos do Homem}

Subcategoria A - Participação

Indicadores: i - Participação na vida política

ii - Poder Efectivo ao Governo

iii - Eleições Livres e Justas

iv - Autonomia eleitoral

v - Eleições executivas livres e justas 
Subcategoria B - Direitos

Indicadores: i-Direitos do Homem

ii - Direitos políticos

iii - Direitos Coletivos

iv - Liberdade de expressão

v - Liberdade de Associação e de Reunião

vi - Liberdade de Imprensa

vii - Direitos civis

viii - Ratificação e relatório de seguimento das convenções internacionais fundamentais sobre os direitos do Homem

Subcategoria C - Paridade

Indicadores: i - Igualdade de géneros

ii - Taxa de sucesso no ensino primário, Feminina

iii - Percentagem de crianças do sexo masculino no ensino primário e secundário

iv - Participação das mulheres na vida activa

v - Representação das mulheres no Parlamento

vi - Direitos das mulheres

vii - Legislação relacionada com violência contra mulheres

\section{Categoria 3 - Desenvolvimento Económico e Sustentável}

Subcategoria A - Gestão Publica

Indicadores: i - Qualidade da administração pública

ii - Qualidade da gestão orçamental

iii - Reservas detidas pelo sistema bancário

iv - Rácio do total das receitas sobre o total da despesa

v - Rácio do défice ou excedente orçamental sobre o PIB

vi - Gestão da dívida pública

vii - Inflação

viii - Rácio do serviço da dívida externa sobre as exportações

ix - Importações cobertas pelas reservas

x - Capacidades estatísticas

Subcategoria B - Sector Privado

Indicadores: i - Ambiente concorrencial

ii - Ambiente económico do sector agrícola e rural

iii - Clima de investimento

iv - Dimensão da burocracia

Subcategoria C - Infraestrutura 
Indicadores: i - Qualidade das infra-estruturas

ii - Acesso a electricidade

iii - Assinantes de Telemóvel

iv - Acesso a equipamento informático

v - Utilização de Internet

Subcategoria D - Ambiente e Sector Rural

Indicadores: i - Ambiente e Sustentabilidade

ii - Papel do ambiente na elaboração da política

iii - Acesso a Água e Terreno para a Agricultura

iv - Acesso a entradas agrícolas e aos mercados de produção

$v$ - Desenvolvimento dos serviços financeiros rurais

vi - Ambiente político e legal das organizações profissionais agrícolas

vii - Alocação e gestão dos recursos públicos em favor do desenvolvimento agrícola e rural

viii - Diálogo entre o governo e organizações profissionais agrícolas

\section{Categoria 4- Desenvolvimento Humano}

Subcategoria A - Saúde e Segurança Social

Indicadores: i - Incidência de Tuberculose

ii - Mortalidade Infantil

iii - Vacinação (DTP)

iv - Regime de segurança social

v - Protecção Social e Trabalho

vi - Grau de exclusão social

vii - Provisão de tratamento anti-retroviral

viii - Provisão de tratamento anti-retroviral para mulheres grávidas

ix - Acesso a água canalizada

$\mathrm{x}$ - Acesso a água melhorada

xi - Acesso a sanitários

xii - Defecação a céu aberto

Subcategoria B - Educação

Indicadores: i - Dispensa e qualidade de ensino

ii - Número de alunos por professor no ensino primário

iii - Taxa de sucesso no ensino primário

iv - Taxa de inscrição no ensino superior

v - Passagem ao Ensino Secundário 
Anexo 2: Indicadores Índice de Prosperidade Legatum

\section{Economia}

Tc PIBpc

Alimentação e Habitação

Capital físico por trabalhador

Confiança nas instituições financeiras

Expectativas económicas

Dimensão e volatilidade do IDE

Poupança interna bruta

Percentagem das exportações dedicada à tecnologia de ponta

Inflação

Dimensão do mercado interno

Percentagem de incumprimento

Percepção da disponibilidade de emprego

Satisfação com os padrões de vida

Taxa de desemprego

\section{Empreendedorismo e Oportunidades}

Custos com a abertura de uma empresa

Ambiência empreendedora

Percentagem de TIC's no total das exportações

Largura de banda da internet

Número de telemóveis per 100 capita

Percepção da relação Trabalhar muito / ser bem sucedido

Gastos em I\&D em percentagem

Direitos de autor recebidos

Segurança dos servidores de internet

Desigualdades Sociais (Educação, emprego, económicas)

\section{Governação}

Corrupção nos negócios e no poder politico

Confiança nos militares

Confiança na liberdade / honestidade eleitoral

Confiança no sistema judicial 
Satisfação com os esforços em lidar com a pobreza

Satisfação com a preservação ambiental

Aprovação governamental

Eficiência governamental

Democraticidade governamental

Constrangimentos políticos

Direitos políticos

Estabilidade do Governo

Nível de regulação

Estado de Direito

Separação de poderes

Participação cívica

\section{Educação}

Rácio de inscrições no ensino primário e secundário feminino / masculino

Rácio de inscrições no ensino secundário

Rácio de inscrições no ensino superior

Rácio de inscrições no ensino primário

Percepção de que as crianças estão a aprender na actualidade

Rácio alunos/professores ao nível do ensino primário

Satisfação com o sistema de educação

Anos de escolaridade secundária por trabalhador

Anos de escolaridade superior por trabalhador

\section{Saúde}

Taxa de mortes provocadas por doenças respiratórias

Gastos na saúde per capita

Problemas de saúde

Esperança média de vida ajustada à saúde

Camas de hospitais per 1000 capita

Incidência de tuberculose

Mortalidade infantil per 1000 nascimentos

Nível de preocupações

Esperança de vida

Taxa de crianças imunes a doenças infecciosas

Taxa de crianças imunes ao sarampo

Índices sanitários 
Satisfação com a beleza do ambiente

Satisfação com a saúde

Taxa de subnutrição

Qualidade das águas

Percepção quanto ao adequado descanso

\section{Segurança}

Capacidade de expressão da opinião política

Assaltos

Guerra civil

Instabilidade demográfica

Grupos de apoio

Migrações

Criminalidade

Refugiados

Segurança quanto a andar sozinho à noite

Violência política patrocinada pelo Estado

\section{Liberdades Pessoais}

Satisfação com a liberdade de escolha

Liberdade civis

Liberdades pessoais

Tolerância para com os imigrantes

Tolerância para com as minorias

\section{Capital Social}

Doações a instituições de caridade

Ajuda a estranhos

Voluntariado

Estado civil

Percepção quanto a apoios sociais

Envolvimento nas causas religiosas

Percentagem das pessoas que confiam nos outros 
Anexo 3: Indicadores Índice de Competitividade Global

Requerimentos Básicos

10 Pilar: Instituições

A. Instituições Públicas

1. Direitos de propriedade

1.01 Direitos de propriedade

1.02 Protecção da propriedade intelectual

2. Ética e corrupção

1.03 Desvio de fundos públicos

1.04 Confiança nos políticos

1.05 Pagamentos irregulares e subornos

3. Abuso de influência

1.06 Independência judicial

1.07 Clientelismo

4. Ineficiência do Governo

1.08 Desperdício de gastos públicos

1.09 Peso da regulamentação governamental

1.10 Eficiência do quadro jurídico

1.11 Eficiência do quadro jurídico

1.12 Transparência da política do Governo

5. Segurança

1.13 Custos empresariais do terrorismo

1.14 Custos empresariais do crime e da violência

1.15 Crime organizado

1.16 Confiança nos serviços policiais

B. Instituições privadas

1. Ética corporativa

1.17 Ética empresarial

2. Prestação de Contas (Accountability)

1.18 Eficácia das auditoria e das normas de avaliação

1.19 A eficácia dos conselhos de administração

1.20 Protecção dos interesses dos accionistas minoritários

1.21 Grau de protecção dos investidores

2ㅇ pilar: Infra-estruturas

A. Infra-estruturas: transportes 
2.01 Qualidade das infra-estruturas

2.02 Qualidade das estradas

2.03 Qualidade das infra-estruturas ferroviárias

2.04 Qualidade das infra-estruturas portuárias

2.05 Qualidade das infra-estruturas de transporte aéreo

2.06 Quilómetros de estradas

B. Energia e Infra-estruturas telefónicas

2.07 Qualidade do fornecimento de electricidade

2.08 Linhas de telefone fixo

2.09 Telemóveis

3o pilar: Ambiente macroeconómico

3.01 Saldo orçamental

3.02 Taxa nacional de poupança

3.03 Inflação

3.04 Taxa de juro

3.05 Dívida pública

3.06 Rating da dívida pública

4o pilar: Saúde e educação primária

A. Saúde

4.01 Impacto da malária nos negócios

4.02 Incidência de malária

4.03 Impacto da tuberculose nos negócios

4.04 Incidência de tuberculose

4.05 Impacto da VIH / SIDA nos negócios

4.06 Incidência de VIH / SIDA

4.07 Mortalidade infantil

4.08 Esperança média de vida

B. Educação primária

4.09 Qualidade da educação primária

4.10 Taxa de escolarização do ensino primário

Factores potenciadores de eficiência

5o pilar: Ensino superior e formação

A. Quantidade da educação

5.01 Taxa de escolarização do ensino secundário 
5.02 Taxa de escolarização do ensino superior

B. Qualidade da educação

5.03 Qualidade do sistema educativo

5.04 Qualidade do ensino da matemática e das ciências

5.05 Qualidade das escolas de Gestão

5.06 Acesso a internet nas escolas

C. Formação no emprego

5.07 Disponibilidade local de pesquisa e serviços especializados de formação

5.08 Alcance da formação de pessoal

6ㅇ pilar: Eficiência do mercado de bens

A. Concorrência

1. Concorrência interna

6.01 Intensidade da concorrência local

6.02 Dimensão da posição dominante no mercado

6.03 Eficácia da regulação anti-monopólio

6.04 Extensão e efeitos da tributação

6.05 Taxas de imposto

6.06 Número de procedimentos necessários para iniciar um negócio

6.07 Tempo necessário para iniciar um negócio

6.08 Custos da política agrícola

2. Concorrência internacional

6.09 Prevalência das barreiras comerciais

6.10 Tarifas comerciais

6.11 Prevalência da propriedade estrangeira

6.12 Impacte nos negócios da regulação sobre IDE

6.13 Encargos dos procedimentos aduaneiros

6.14 Importações em percentagem do PIB

B. Qualidade da procura

6.15 Nível da orientação dos clientes

6.16 Sofisticação dos compradores

7ㅇ pilar: Eficiência do mercado de trabalho

A. Flexibilidade

7.01 Cooperação nas relações laborais

7.02 Flexibilidade de determinação dos salários

7.03 A rigidez do emprego 
7.04 Políticas de admissão e de despedimento

7.05 Despesas de despedimento

7.06 Extensão e efeitos da tributação

B. Emprego eficiente dos talentos

7.07 Remuneração e produtividade

7.08 Confiança na gestão profissional

7.09 Fuga de cérebros

7.10 Participação feminina na força de trabalho

8o pilar: Desenvolvimento dos mercado financeiros

A. Eficiência

8.01 Disponibilidade de serviços financeiros

8.02 Acessibilidade dos serviços financeiros

8.03 Financiamento através dos mercados de capitais locais

8.04 Facilidade de acesso ao crédito

8.05 Disponibilidade de capital de risco

8.06 Restrição sobre os fluxos de capital

B. Fiabilidade e confiança

8.07 Solidez da banca

8.08 Regulação das bolsas de valores

8.09 Índice de direitos legais

9ㅇp pilar: Dinâmica tecnológica

A. Adopção tecnológica

9.01 Disponibilidade de tecnologia de ponta

9.02 Absorção de tecnologia ao nível da empresa

9.03 IDE e transferência de tecnologia

B. Utilização das TIC

9.04 Utilizadores da Internet

9.005 Assinaturas de Internet de banda larga

9.06 Largura de banda da internet

9.07 Linhas de telefone fixo

9.08 Telemóveis

10 pilar: dimensão do mercado

A. dimensão do mercado interno 
10.01 Índice de dimensão do mercado interno

B. dimensão do mercado externo

10.02 Índice de dimensão do mercado externo

Factores de inovação e sofisticação

11 p pilar: Sofisticação dos negócios

11.01 Quantidade de fornecedores locais

11.02 Qualidade de fornecedores locais

11.03 Estado de desenvolvimento dos clusters

11.04 Natureza da vantagem competitiva

11.05 Amplitude da cadeia de valores

11.06 Controle de distribuição internacional

11.07 Sofisticação dos processos produtivos

11.08 Alcance do marketing

11.09 Disposição para delegar autoridade

11.10 Confiança na gestão profissional

12ำ pilar: Inovação

12.01 Capacidade para a inovação

12.02 Qualidade das instituições de investigação científica

12.03 Gastos empresariais em I\&D

12.04 Colaboração entre a universidade e a indústria em I \& D

12.05 Compras governamentais de produtos com tecnologia de ponta incorporada

12.06 Disponibilidade de cientistas

12.07 Patentes

12.08 Protecção da propriedade intelectual 


\section{O CEsA}

O CEsA é um dos Centros de Estudo do Instituto Superior de Economia e Gestão da Universidade Técnica de Lisboa, tendo sido criado em 1982.

Reunindo cerca de vinte investigadores, todos docentes do ISEG, é certamente um dos maiores, senão o maior, Centro de Estudos especializado nas problemáticas do desenvolvimento económico e social existente em Portugal. Nos seus membros, na maioria doutorados, incluem-se economistas (a especialidade mais representada), sociólogos e licenciados em direito.

As áreas principais de investigação são a economia do desenvolvimento, a economia internacional, a sociologia do desenvolvimento, a história africana e as questões sociais do desenvolvimento; sob o ponto de vista geográfico, são objecto de estudo a África Subsariana, a América Latina, a Ásia Oriental, do Sul e do Sudeste e o processo de transição sistémica dos países da Europa de Leste.

Vários membros do CEsA são docentes do Mestrado em Desenvolvimento e Cooperação Internacional leccionado no ISEG/"Económicas". Muitos deles têm também experiência de trabalho, docente e não-docente, em África e na América Latina.

\section{Os autores}

\section{LUÍS MAH}

Luís Mah é actualmente investigador de pós-doutoramento no CEsA com uma bolsa da FCT e a desenvolver trabalho na área da democratização e desenvolvimento na África subsariana. Nos últimos anos trabalhou na Oikos e depois na Objectivo 2015- Campanha do Milénio das Nações Unidas. Fez o doutoramento em Estudos de Desenvolvimento na London School of Economics (LSE) com uma tese sobre o papel do Estado no desenvolvimento (com um estudo de caso sobre a Coreia do Sul). Foi correspondente na Ásia para o semanário

Independente e editor na Lusa-Macau.

\section{BRUNO DAMÁSIO}

Finalista do curso de Economia pelo Instituto Superior de Economia e Gestão da Universidade Técnica de Lisboa (ISEG / UTL), investigador no Centro de Estudos Sobre África e do Desenvolvimento (CESA), inscrito no Mestrado de Econometria Aplicada e Previsão do mesmo instituto.

Área de interesse: Econometria aplicada aos Estudos do Desenvolvimento.

\section{Centro de Estudos sobre África e do Desenvolvimento}

Instituto Superior de Economia e Gestão (ISEG/"Económicas")

da Universidade Técnica de Lisboa

R. Miguel Lupi, 20

Tel: + / $351 / 213925983$
1249-078 LISBOA

Fax: [...] 213976271
PORTUGAL

e-mail: cesa@iseg.utl.pt

URL: http://www.iseg.utl.pt/cesa 